\title{
Impact of Infection Dose and Previous Serum Antibodies against the Locus of Enterocyte Effacement Proteins on Escherichia coli 0157:H7 Shedding in Calves following Experimental Infection
}

\author{
L. Martorelli, ${ }^{1}$ C. J. Hovde, ${ }^{2}$ D. A. Vilte, ${ }^{1}$ A. Albanese, ${ }^{3}$ E. Zotta, ${ }^{3}$ C. Ibarra, ${ }^{3}$ \\ R. J. C. Cantet, ${ }^{4}$ E. C. Mercado, ${ }^{1}$ and A. Cataldi ${ }^{5}$ \\ ${ }^{1}$ Instituto de Patobiología, CICVyA, INTA, 1686 Hurlingham, Argentina \\ ${ }^{2}$ School of Food Science, University of Idaho, Moscow, ID 83844-3025, USA \\ ${ }^{3}$ Laboratorio de Fisiopatogenia, Departamento de Fisiología, Facultad de Medicina, Universidad de Buenos Aires, \\ 1121 Ciudad Autónoma de Buenos Aires, Argentina \\ ${ }^{4}$ Facultad de Agronomía, Universidad de Buenos Aires-CONICET, 1417 Ciudad Autónoma de Buenos Aires, Argentina \\ ${ }^{5}$ Instituto de Biotecnología, CICVyA, INTA, 1686 Hurlingham, Argentina
}

Correspondence should be addressed to A. Cataldi; cataldi.angeladrian@inta.gob.ar

Received 30 January 2015; Revised 5 May 2015; Accepted 5 May 2015

Academic Editor: Anjali Joshi

Copyright (C) 2015 L. Martorelli et al. This is an open access article distributed under the Creative Commons Attribution License, which permits unrestricted use, distribution, and reproduction in any medium, provided the original work is properly cited.

Escherichia coli $\mathrm{O} 157: \mathrm{H} 7$ is the main causative agent of haemolytic uremic syndrome. Cattle are the main reservoir of these bacteria, and have been shown to develop immune response to colonization. Our aim was to investigate the faecal shedding pattern of $E$. coli O157:H7 in calves challenged intragastrically with either $10^{8}$ or $10^{10} \mathrm{CFU}$, as well as the ability of specific preexisting antibodies to reduce shedding of the pathogen. Shedding was analysed by direct counting as well as enrichment of rectoanal mucosal swabs. Statistical analysis was performed using a linear model for repeated measures with and without the inclusion of preexisting antibodies against the carboxy-terminal fraction of intimin- $\gamma$ ( $\gamma$-intimin C280) as a covariable. Results suggest that there is a statistical difference in the area under the shedding curves between both doses for 14 as well as 28 days after challenge $(p=0.0069$ and 0.0209 , resp.). This difference is increased when the prechallenge antibodies are taken into account $(p=0.0056$ and 0.0185$)$. We concluded that the bacterial dose influences shedding on calves experimentally challenged and that preexisting antibodies against E. coli $\mathrm{O} 157: \mathrm{H} 7 \gamma$-intimin C280 could partially reduce faecal excretion.

\section{Introduction}

Enterohaemorrhagic Escherichia coli (EHEC) O157:H7 is a major etiologic agent of diseases in humans, whose clinical spectrum includes diarrhoea, haemorrhagic colitis, and haemolytic uremic syndrome (HUS), the leading cause of chronic renal failure in children in Argentina and several other countries $[1,2]$.

Cattle are the main reservoir of EHEC O157:H7, which predominately colonizes the lymphoid follicle-dense mucosa at the terminal rectum and the rectoanal junction (RAJ) [3]. Faecal contamination of meat during slaughter, the use of raw faeces as fertilizers, and the contamination of drinking water are the major ways by which this microorganism can enter the human food chain [4-6].

This bacterium produces Shiga toxins types 1 and/or 2 [79], which are responsible for systemic damage, particularly of the vascular endothelium of kidneys and brain, with severe renal and neurological sequelae in children and the elderly. In addition to Shiga toxins, E. coli O157:H7 is characterized by other virulence-associated traits which enables it to colonize the intestinal mucosa of humans and animals with a characteristic histopathological lesion known as "attaching and effacing" (A/E). A large chromosomal pathogenicity island 
called Locus of Enterocyte Effacement (LEE) is associated with A/E activity [10-12]. The LEE encodes a type three secretion system (TTSS) that translocates effector proteins responsible for the $\mathrm{A} / \mathrm{E}$ lesion into the host cell. Intimin, a bacterial outer membrane protein, binds to Tir, the translocated intimin receptor in the host cell membrane, and this binding leads to the formation of the A/E lesion. Tir, EspB, and other LEE-encoded proteins are translocated into the host cell through a transiently produced filamentous structure [13], which consists of an assembly of EspA subunits [14] and contributes, in turn, to the creation of a pore in the eukaryotic cell membrane.

Ample evidence suggests that infected animals can excrete the bacteria in their faeces from a few days to months $[6,15]$. Key features associated with the rate of colonization are the age of the animals and genetic markers in the pathogen.

Many virulence factors of $E$. coli $\mathrm{O} 157: \mathrm{H} 7$ induce an immune response during the course of natural as well as experimental infections in cattle. Oral inoculation of calves and steers with E. coli $\mathrm{O} 157: \mathrm{H} 7$ promotes an increase in serum antibody titres against the $\mathrm{O} 157$ lipopolysaccharide and neutralizing antibodies to Shiga toxins. Recently, Bretschneider et al. [16] demonstrated that cattle respond serologically to Intimin and $\mathrm{EspB}$ of E. coli O157:H7 during the course of experimental infection. Furthermore, several authors have reported that calves and cattle shed fewer bacteria after several experimental inoculations, which could be related to a partially protective immune response elicited by the pathogen [17-19].

Vaccination is one of the preslaughter interventions that shows promise to reduce EHEC O157:H7 occurrence in cattle. We, along with other groups, have demonstrated that vaccination of calves with type three secretion injection apparatus proteins results in reduced excretion of EHEC O157:H7 after experimental infection in cattle with an oral challenge dose of $10^{10} \mathrm{CFU}$ [20-23].

We therefore assessed if the level of colonization depends on the bacterial challenge dose and whether previous antibodies against the carboxy-terminal fraction of $\gamma$-intimin $(\gamma$ intimin C280) could reduce faecal excretion of the pathogen. Furthermore we assessed the humoral immune response elicited in response to the challenge. For this purpose, we compared the effect of two different doses of oral inoculation in calves regarding the colonization status and the associated serum immune response with shedding.

\section{Materials and Methods}

2.1. Animals. Nine four-month-old conventionally reared Holando-Argentino male calves were obtained from a dairy farm in Buenos Aires Province, Argentina, and housed in biosafety level 2 containments rooms at the Instituto Nacional de Tecnología Agropecuaria (INTA) Experimental Station. All calves were acclimatized to the containments room for 1 week prior to the challenge and were deemed healthy by clinical examination and treated prophylactically upon arrival with $1 \%$ ivermectin to control intestinal nematodes. Calves were fed alfalfa pellets, with free access to hay and water.
Prior to the challenge, calves were confirmed twice (one month and three days before inoculation) to be negative for E. coli $\mathrm{O} 157: \mathrm{H7}$ by enrichment of rectoanal mucosal swabs followed by immunomagnetic separation, and serum specific antibodies were also assessed as described below. All animal experiments were performed with the approval of the INTA Animal Welfare Committee.

2.2. Strain. The challenge strain of E. coli O157:H7 selected for the experimental infection was $438 / 99$. This strain was isolated from a healthy cow and was used previously in experimental studies [22]. It was selected for spontaneous resistance to nalidixic acid to facilitate recovery from rectoanal mucosal swabs and tissues and possesses the genes for enterohemolysin, $\gamma$-intimin, EspA, EspB, Stx2, and the pO157 plasmid.

2.3. Experimental Infection. Animals were randomly assigned to Groups $1(n=5)$ and $2(n=4)$ and challenged intragastrically with the bacterium. Group 1 received $10^{8} \mathrm{CFU}$, whereas Group 2 was challenged with a dose of $10^{10} \mathrm{CFU}$ of E. coli O157:H7 strain 438/99 in $15 \mathrm{~mL}$ of sterile PBS. Randomization was performed to assure that both groups were composed of animals with similar weight distribution (approximately 100 and $120 \mathrm{~kg}$, resp.).

2.4. Sample Collection. Rectoanal mucosal swabs were taken at $0,2,5,8,11,14,17,20,24$, and 28 days after the challenge [24]. In addition, serum samples were taken at $0,8,17$, and 28 days after the oral bacterial challenge. Necropsy was performed at day 28 after challenge and tissue sections from the ileum, cecum, and rectoanal junction were obtained and evaluated for the presence of bacteria and mucosal antibodies and for histopathology.

One animal from Group 2 was euthanized 20 days after the challenge for health issues according to the INTA Animal Welfare Committee standards.

2.5. E. coli O157:H7 Shedding. The magnitude and duration of the fecal excretion of viable E. coli O157:H7 were followed by culture of rectoanal mucosal swabs, as previously described [25]. Briefly, bacterial CFU/swab was determined by vortexing the swabs in Trypticase soy broth (TSB, Oxoid, Basingstoke, UK), plating serial dilutions on Sorbitol MacConkey agar (Oxoid, Basingstoke, UK) containing $20 \mu \mathrm{g} / \mathrm{mL}$ nalidixic acid (Sigma, St. Louis, USA), $2.5 \mu \mathrm{g} / \mathrm{mL}$ potassium tellurite, and $0.05 \mu \mathrm{g} / \mathrm{mL}$ cefixime (CT-SMAC). When direct cultures were negative, swabs were enriched at $37^{\circ} \mathrm{C}$ for $18 \mathrm{~h}$ and $1 \mathrm{~mL}$ of this culture was subjected to E. coli $\mathrm{O} 157$ immunomagnetic separation (IMS) performed according to the manufacturer's instructions (Dynabeads anti-E. coli O157, Invitrogen Dynal AS, Oslo, Norway). The bead-bacterium mixture was plated on CT-SMAC. Samples that resulted culture-positive by IMS were considered positive (10 CFU), while samples culture-negative by IMS were deemed negative. Non-sorbitol-fermenting colonies were tested for E. coli O157 LPS by latex agglutination (Oxoid, Basingstoke, UK) and confirmed by a multiplex PCR for the stx1, stx2, eae, and rfbO157 genes [26-28]. Tissues obtained at necropsy were 
cultured to detect E. coli O157:H7 after IMS as described above.

2.6. Production of Recombinant E. coli O157:H7 Proteins. EspB and $\gamma$-intimin C280 genes from the E. coli O157:H7 strain $146 \mathrm{~N}$ were cloned in pRSET-A vector (Invitrogen Corp., Carlsbad, CA) and expressed in E. coli BL21 (D3)/pLysS, as described previously [29]. The aminoterminal-His-tagged proteins were purified from the lysates by affinity chromatography on nickel-agarose columns (ProBond nickel-chelating resin; Invitrogen Corp.), eluted under denaturing conditions, and dialyzed in PBS at pH 7.4.

2.7. Antibody Response. All sera samples taken before and during the experiment were analyzed by ELISA to detect specific antibodies against $E$. coli proteins EspB and $\gamma 280$-intimin as described elsewhere [29]. Briefly, 96-well Nunc-Immuno MaxiSorp assay plates (Nunc, Roskilde, Denmark) were coated overnight at $4^{\circ} \mathrm{C}$ with $100 \mu \mathrm{L}$ of either $\gamma 280$-intimin or EspB at $1 \mu \mathrm{g} / \mathrm{mL}$ in carbonate buffer $\mathrm{pH}$ 9.6. After three washes with PBS pH 7.4 containing $0.05 \%$ Tween 20 (PBS$\mathrm{T}$ ), nonspecific binding sites were blocked with $3 \%$ skimmed milk in PBS for $1 \mathrm{~h}$ at $37^{\circ} \mathrm{C}$. After that, washes were repeated, and sera diluted $1 / 50$ in PBS-T were added $(100 \mu \mathrm{L} /$ well). Plates were incubated for $2 \mathrm{~h}$ at $37^{\circ} \mathrm{C}$. For each plate, two wells were incubated with PBS-T alone (negative control), and a known positive sample was included. Each sample was analyzed in duplicate. After washing with PBS-T, wells were incubated for another hour with $100 \mu \mathrm{L}$ of sheep anti-bovine IgG, IgG1, IgG2, or IgA conjugated with horseradish peroxidase (Bethyl Laboratories, Montgomery, USA), at dilutions of 1:10000 in PBS-T. Plates were washed three times with PBS-T. Finally, ABTS [2,2-azino-di (3-ethyl-benzthiazoline sulphonic acid)] (Amresco, Solon, USA) in citrate-phosphate buffer $\mathrm{pH} 4.2$ plus $0.01 \% \mathrm{H}_{2} \mathrm{O}_{2}(100 \mu \mathrm{L} /$ well $)$ was added. Reactions were stopped after $10 \mathrm{~min}$ with $100 \mu \mathrm{L} /$ well of $5 \%$ SDS and read at $405 \mathrm{~nm}\left(\mathrm{OD}_{405}\right)$ in a BioTek ELx808 microplate reader (BioTek Instruments, Winooski, USA). Mucosal antibodies from intestinal tissue samples taken at necropsy were obtained as described elsewhere [30] and assessed by ELISA for the presence of specific antibodies as described above. The specificity of antibodies was confirmed by Western blot.

2.8. Histopathological Examination. One segment of ileum, cecum, and rectoanal junction (approximately $20 \mathrm{~g}$ each) from each animal was obtained at necropsy and immediately fixed in neutral buffered $10 \%$ formalin, dehydrated with alcohol, and embedded in paraffin. Sagittal cuts $(5 \mu \mathrm{m})$ were made with a microtome (Leica RM 2125, Wetzlar, Germany), stained with hematoxylin and eosin (H\&E), and mounted on $2 \%$ silane-coated slides. Tissue sections were observed by light microscopy (Nikon Eclipse 200, NY, USA).

2.9. Immunohistochemistry. Immunohistochemistry was performed on tissue segments that were positive for $E$. coli O157:H7 culture, as described above. Briefly, dewaxed sections were blocked for endogenous peroxidase with $\mathrm{H}_{2} \mathrm{O}_{2}$
$3 \%$ in methanol for $10 \mathrm{~min}$. Later, the slides were preincubated with no immune rabbit serum at room temperature for $30 \mathrm{~min}$. Then, the primary rabbit anti-O157 LPS antibody, which was kindly provided by Susana Bruno (Antisera Service (ANLIS, Argentina)), was added (1:100). The sections were incubated with the primary antibody in a humidity chamber at $4^{\circ} \mathrm{C}$ overnight. The immunoperoxidase technique was then performed following the protocol from the RTU Vectastain Kit (Vector, Peterborough, UK). The antigen was revealed by diaminobenzidine (DAB, Vector). Finally, the sections were counterstained by Meyer's Hematoxylin and mounted for observation. Specificity tests were performed by omitting the primary antiserum in the staining.

2.10. Statistical Analysis. Data analyzed were bacterial shedding of calves and levels of antibodies. To attain normality, both set of variables were transformed using procedures described by Box and Cox [31]. The transformation parameter was obtained after a grid search in the open interval $(-0.95$, $0.95)$. Resulting variables were analyzed using linear models for repeated measures [32], as in Vilte et al. [22, 23].

For the transformed CFU (TCFU) variable describing the shedding of calves effects in the model were dose of $E$. coli $\mathrm{O} 157: \mathrm{H7}$ (as a classification variable with two levels: $10^{8}$ and $10^{10} \mathrm{CFU}$ ), the covariate initial level of antibodies nested within dose (i.e., one covariate per dose), and a linear term for the covariate day of measure interacting with dose, so as to account for the daily trend within treatment. The dependence structure among repeated measures within animal within dose was modeled with a Gaussian covariance matrix. The area under the curve (AUC) was obtained using estimable linear functions [33]. The hypothesis of interest was whether the estimated AUC from the two doses differ at different times (14 and 28 days), and including or excluding the effect of the initial antibody level. All tests of hypotheses had their degrees of freedom corrected by the procedure of Kenward and Roger [34], and $p$ values smaller than 0.05 were considered to be significant.

Differences in antibodies were tested from either estimable contrasts or differences in least-square means [33]. Models used included different effects according to antibody. In all cases, the residual covariance structure was 4-banded Toeplitz for the four different measures, within animal. All analyses were performed using Proc Mixed of SAS version 9.2 (SAS, 2013).

\section{Results}

3.1. E. coli O157:H7 Shedding after Challenge. In order to observe the effect of challenge dose on total shedding and kinetics of $E$. coli $\mathrm{O} 157: \mathrm{H} 7$, two groups of calves were orally challenged either with $10^{8}$ or with $10^{10} \mathrm{CFU}$ of E. coli O157:H7. The kinetics of fecal shedding in both groups is shown in Figure 1. To understand if there is a relationship between dose and fecal shedding, we performed a statistical analysis using a linear model for repeated measures (SAS) analysis (Table 1). All main effects and covariates displayed a highly significant effect on TCFU: dose $10^{10}$ produced more TCFU 


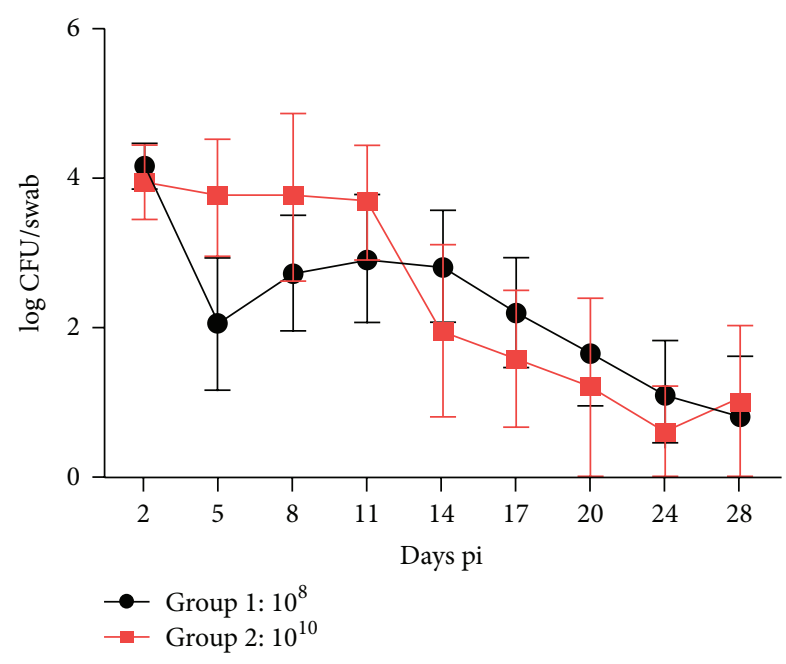

FIGURE 1: Shedding pattern of calves inoculated with either $10^{8}$ or $10^{10} \mathrm{CFU}$ of E. coli O157:H7. Data are shown as log CFU/swab \pm S.E.M.

than $10^{8}$. For the covariable anti- $\gamma$-intimin C280 antibody (dose), the higher the level of antibodies the smaller the number of TCFU. Finally, the linear covariate dose by day showed smaller levels as the days passed. Cubic and quadratic responses (not shown in Table 1) were far from being significant. When anti-EspB antibodies were used as covariable, no significant effect of the TCFU was observed. The results of the tests of hypothesis of differences in AUC by dose are displayed in Table 2. All tests produced significant differences in AUC due to dose and day (14 or 28).

There was a significant difference in shedding between the groups. The calves that received $10^{8} \mathrm{CFU}$ shed fewer bacteria for 14 days as well as 28 days, compared to the ones that were challenged with $10^{10} \mathrm{CFU}$. When the levels of preexisting IgG antibodies against $\gamma$-intimin C280 were considered in the model, the difference became even more significant (see $p$ values in Table 2).

One animal from each group was excreting E. coli O157:H7 on day 28 after the challenge, and the challenge strain was isolated from rectoanal junction tissue obtained from these animals at necropsy. The bacterium was also detected by immunohistochemistry (see below).

\subsection{Humoral Immune Response to E. coli O157:H7 Challenge.} Serum IgG and IgA antibodies were assessed by ELISA on the day of E. coli O157:H7 challenge $(0 \mathrm{dpc})$ and at different time points after the challenge. Results are shown in Figure 2. As expected, specific IgG was higher than IgA for both antigens tested. Furthermore, most of the IgG was IgG1, whereas IgG2 was very low (data not shown). Higher $\mathrm{OD}_{405}$ values were obtained for IgG antibodies against EspB than against $\gamma$ intimin C280, and these levels were very similar for both groups.

IgA response against any of the antigens was not detected in the group that received $10^{10} \mathrm{CFU}$ whereas the level of IgA specific for both antigens rose in the calves challenged with the lowest dose reaching, at day 8 after the challenge, levels similar to those of IgG. In spite of this, the difference was not statistically significant.

No neutralizing activity against Stx2 was observed (data not shown).

3.3. Mucosal Immune Response to E. coli O157:H7 Challenge. Specific mucosal IgG and IgA antibodies were assessed in tissue segments of rectoanal junction, ileum, and cecum. Results are shown in Figure 3.

IgG against both EspB and $\gamma$-intimin C280 was found significantly higher than IgA in both groups in the three segments assessed $(p<0.0001)$.

$\mathrm{IgG}$ and $\operatorname{IgA}$ antibodies against EspB were significantly higher in RAJ and cecum of Group 2 than in Group 1, whereas no significant differences were found in antibodies against $\gamma$ intimin C280 between groups.

3.4. Histopathology. Upon histopathological examination, ileum and cecum from Groups 1 and 2 presented histological signs of inflammation and mild epithelial necrosis with detachment of the surface epithelium (Figure 4 Supplementary Material, in Supplementary Material available online at http://dx.doi.org/10.1155/2015/290679). Taking into account that the preferential attachment site of the bacteria is the rectoanal junction, it is important to mention that a normal histoarchitecture with polymorphonuclear leukocytes infiltrations was observed in this tissue (Figure 4 Supplementary Material).

3.5. Immunohistochemistry. E. coli $\mathrm{O} 157: \mathrm{H} 7$ was detected by using an antibody against $\mathrm{O} 157$ in segments of rectoanal junction of two calves that continued to excrete at day 28 after inoculation (Figure 5 Supplementary Material).

\section{Discussion}

During this study, two groups of randomly assigned calves were intragastrically challenged with either $10^{8}$ or $10^{10} \mathrm{CFU}$ of E. coli O157:H7. We observed a statistically significant difference in the area under the shedding curves between the two doses of bacterial challenge used in this study for both 14 and 28 days, the group that received the lower dose being the one that shed less bacteria, suggesting a relationship between the challenge dose and the bovine intestinal colonization.

Furthermore, when the preexisting antibodies against $\gamma$ intimin C280 were included in the model, this difference became even more significant. This finding suggests that previous antibodies against this protein could partially reduce E. coli $\mathrm{O} 157: \mathrm{H} 7$ carriage in calves.

Intimin has been shown to be a target of humoral immune responses in different host species and animal models such as humans [35-37], cattle [16, 20-23, 29], rabbits [24], pigs [38], and mice $[39,40]$. These antibodies have been proved to be effective in avoiding epithelial colonization by E. coli O157:H7 [41] and can be obtained through vaccination [20-23] as well as experimental infections [22,23]. However, this response is not completely protective since animals continue to excrete 

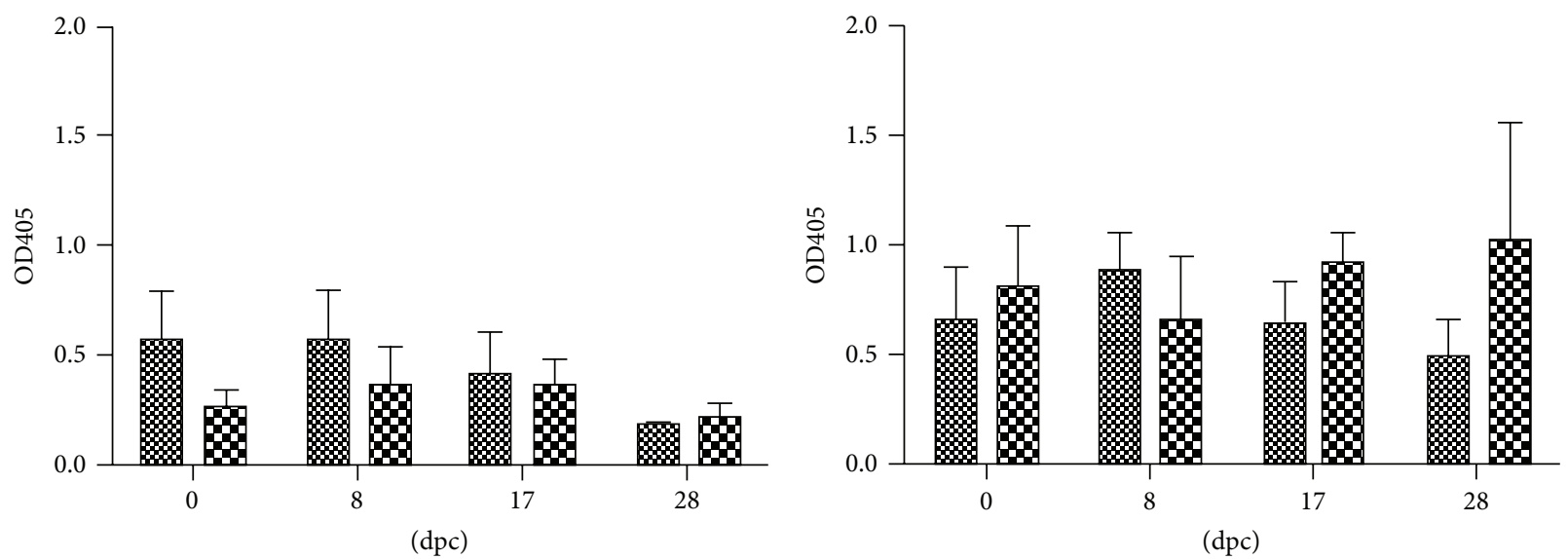

\$ Group 1

88 Group 1

Bo Group 2

(a)

(b)

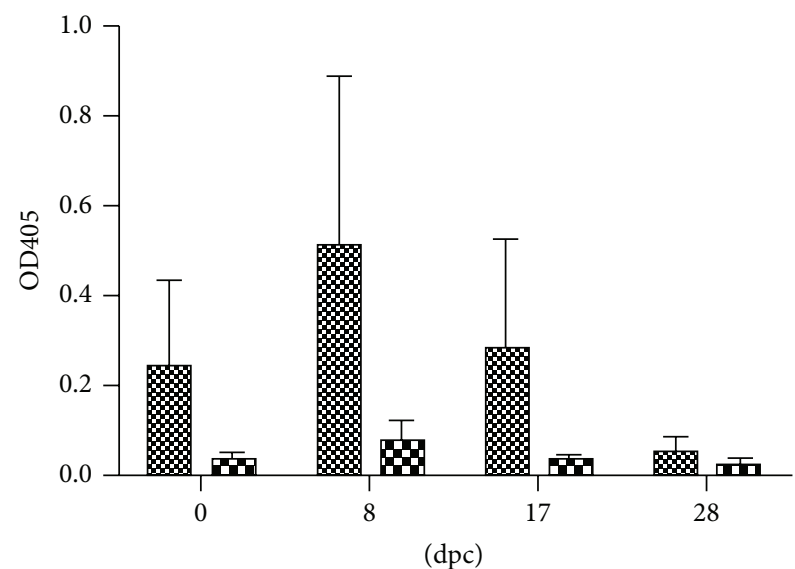

$\$$ Group 1

Doup 2

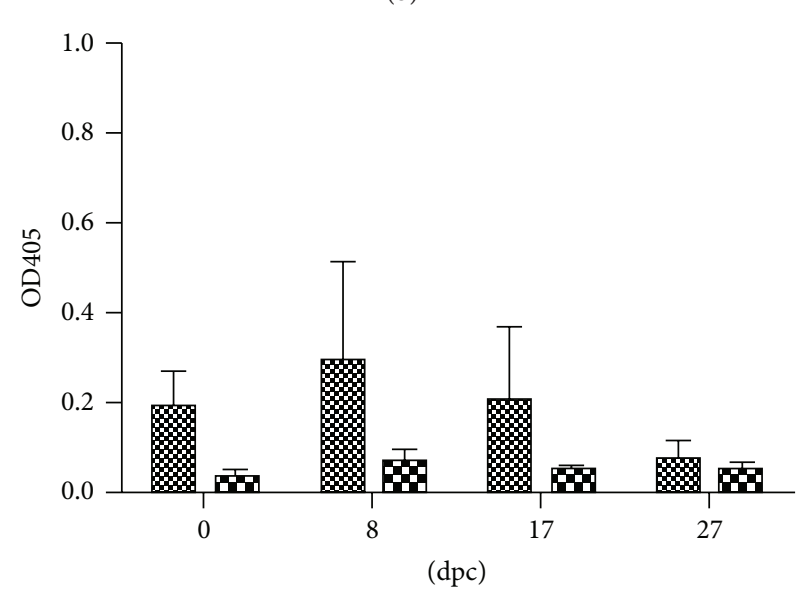

86 Group 1

Q0. Group 2

(c)

(d)

Figure 2: IgG ((a), (b)) and IgA ((c), (d)) antibodies against $\gamma$-intimin C280 ((a), (c)) and EspB ((b), (d)) in calves challenged with $10^{8}$ or $10^{10} \mathrm{CFU}$ of E. coli O157:H7. Data are shown as mean OD405 \pm S.E.M.

TABLE 1: Tests of the effects into the model for transformed CFU.

\begin{tabular}{|c|c|c|c|c|}
\hline Effect & Numerator df & Denominator df & $F$-value & $\operatorname{Pr}<F$ \\
\hline Dose & 2 & 36.4 & 57.63 & $<0.0001$ \\
\hline $\begin{array}{l}\text { Anti- } \gamma \text {-intimin C280 } \\
\text { antibody (dose) }\end{array}$ & 2 & 33.5 & 8.58 & 0.0010 \\
\hline $\begin{array}{l}\text { Anti-EspB } \\
\text { antibody (dose) }\end{array}$ & 2 & 35.4 & 0.72 & 0.4944 \\
\hline Day $\times$ dose & 2 & 40.4 & 16.77 & $<0.0001$ \\
\hline
\end{tabular}

TABLE 2: Test of hypotheses on differences of areas under the curve for different doses and at different days.

\begin{tabular}{|c|c|c|c|c|}
\hline Null hypothesis & $\begin{array}{c}\text { Covariate level of } \\
\text { antibody considered }\end{array}$ & Day & Result of the estimate & $p$ value \\
\hline $\mathrm{AUC} 1=\mathrm{AUC} 2$ & No & 14 & AUC $1<$ AUC 2 & 0.0069 \\
\hline $\operatorname{AUC} 1=\operatorname{AUC} 2$ & Yes & 14 & AUC $1<$ AUC 2 & 0.0056 \\
\hline $\operatorname{AUC} 1=\operatorname{AUC} 2$ & No & 28 & AUC $1<$ AUC 2 & 0.0209 \\
\hline $\mathrm{AUC} 1=\mathrm{AUC} 2$ & Yes & 28 & AUC $1<$ AUC 2 & 0.0185 \\
\hline
\end{tabular}




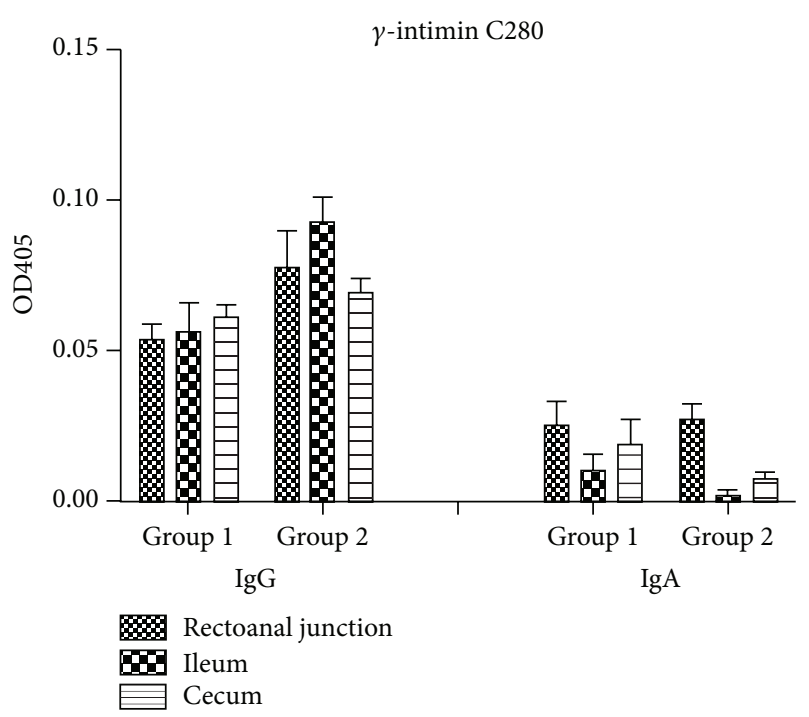

(a)

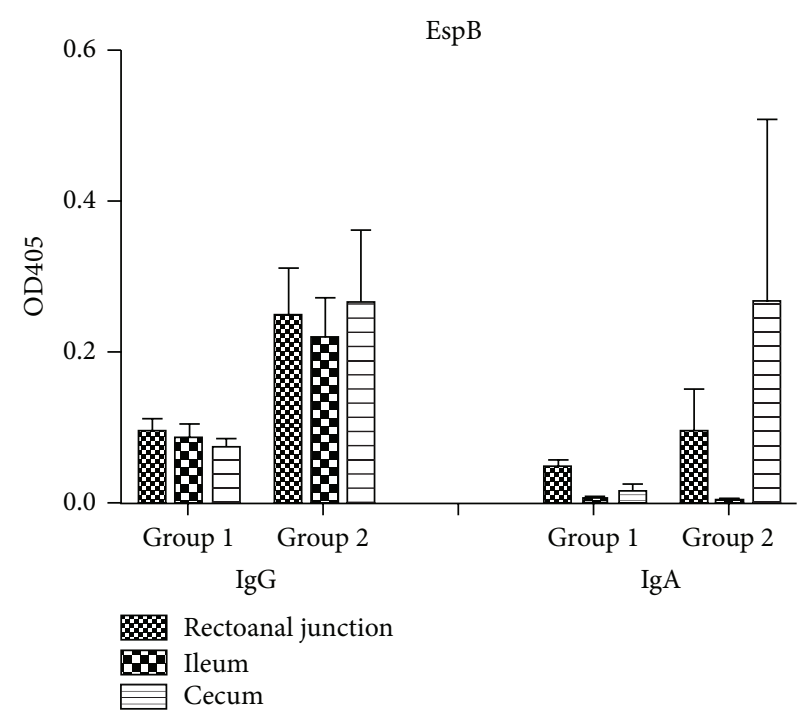

(b)

Figure 3: Mucosal IgG and IgA antibodies against EspB and $\gamma$-intimin C280 in calves challenged with 10 ${ }^{8}$ or $10^{10} \mathrm{CFU}$ of E. coli O157:H7. Data are shown as mean OD405 \pm S.E.M.

the bacteria despite a reduction in shedding and can be reinfected. In the present conditions, we cannot differentiate if the preexisting antibodies against $\gamma$-intimin C280 came from passive immunization through colostrum from their mothers after birth or from the fact that animals were infected by EHEC in the field.

During this study, we did not observe a statistically significant increase in serum antibodies after challenge against any of the antigens tested. However, there was a difference between IgG and IgA antibodies, which could be explained considering that IgG concentration in bovine serum is higher than IgA and has a longer half-life [42, 43].

Interestingly, no IgA response was detected against either EspB or $\gamma$-intimin C280 in the serum of calves from Group 2. Naylor et al. [17] have demonstrated that young calves develop serum IgG and IgA antibody responses to O157 and $\mathrm{H} 7$, and the IgA but not $\operatorname{IgG}$ titers decreased after colonization following a repeated challenge. Furthermore, it was found [16] that the IgA titers decreased only to factors having a known (Eae and Tir) or highly probable function in colonization (EspB), whereas those to O157 increased. These results suggest that serum IgA antibodies against virulence factors involved in colonization may be consumed in response to challenge.

A mild mucosal immune response was observed in both groups in response to E. coli O157 challenge, with higher IgG than IgA antibody levels, as expected, since this immunoglobulin predominates in the mucosa of ruminants [44]. Significantly higher levels of IgG and IgA antibodies against EspB were found in RAJ and cecum of the calves that received the higher dose of bacteria. Interestingly, these animals had very low levels of IgA antibodies in serum. These results suggest that the challenge dose influences the colonization rate and the immune response elicited, at least, in some mucosal epitheliums. Nart et al. [30] have shown that the E. coli $\mathrm{O} 157: \mathrm{H} 7$ colonization induces a local mucosal antibody response, which is directed at several membrane-associated and secreted proteins. Similarly, adult cattle develop colonic and rectal mucosal antibodies of the IgG and IgA classes to E. coli O157:H7 antigens following experimental infection; however, these titers are low [16]. This could be explained by the evidence provided by Hoffman et al. [45] who suggested that Stx2 produced by E. coli O157:H7 during the course of infection may reduce lymphoproliferative responses in intraepithelial as well as peripheric lymphocytes. By contrast, the strain used in our study was Stx2+. Therefore, its immunosuppressive effect must be taken into account since it could explain the low mucosal antibody response that was observed. It would be interesting to further study this response in other mucosal sites such as saliva or nasal swabs.

This study has led us to conclude that the dose of experimental challenge with E. coli $\mathrm{O} 157: \mathrm{H} 7$ influences the colonization rate on the bovine intestinal tract and that preexisting antibodies against $\gamma 280$-intimin may have a protective role against colonization. We have also concluded that oral experimental challenge with a Stx2+ strain induces a mild mucosal immune response.

This finding suggests a relationship between colonization, shedding, and immunity. Although further studies are required to elucidate the role of antibodies and cellular immunity in the excretion dynamics of E. coli O157:H7, the enhancement of immune responses can be proposed as a potential prophylactic measure to control bovine carriage of E. coli $\mathrm{O} 157: \mathrm{H7}$.

\section{Conflict of Interests}

The authors declare that there is no conflict of interests regarding the publication of this paper. 


\section{Acknowledgments}

The present study was supported by PICT 0118 Grant from FONCYT (Argentina). C. Ibarra and A. Cataldi are CONICET fellows. C. J. Hovde was supported by NIH NIGMS Grant no. P20 GM103408. The authors thank Julia Sabio y García for her critical reading, Lucas Vagnoni for expert care and handling of animals, and Laura González for her technical assistance.

\section{References}

[1] H. Karch, P. I. Tarr, and M. Bielaszewska, "Enterohaemorrhagic Escherichia coli in human medicine," International Journal of Medical Microbiology, vol. 295, no. 6-7, pp. 405-418, 2005.

[2] H. A. Repetto, "Long-term course and mechanisms of progression of renal disease in hemolytic uremic syndrome," Kidney International, Supplement, vol. 68, no. 97, pp. S102-S106, 2005.

[3] L. J. Grauke, I. T. Kudva, J. W. Yoon, C. W. Hunt, C. J. Williams, and C. J. Hovde, "Gastrointestinal tract location of Escherichia coli O157:H7 in ruminants," Applied and Environmental Microbiology, vol. 68, no. 5, pp. 2269-2277, 2002.

[4] S. J. Olsen, G. Miller, T. Breuer et al., "A waterborne outbreak of Escherichia coli O157:H7 infections and hemolytic uremic syndrome: Implications for rural water systems," Emerging Infectious Diseases, vol. 8, no. 4, pp. 370-375, 2002.

[5] L. Meichtri, E. Miliwebsky, A. Gioffré et al., "Shiga toxinproducing Escherichia coli in healthy young beef steers from Argentina: prevalence and virulence properties," International Journal of Food Microbiology, vol. 96, no. 2, pp. 189-198, 2004.

[6] H. S. Hussein and L. M. Bollinger, "Prevalence of Shiga toxinproducing Escherichia coli in beef cattle," Journal of Food Protection, vol. 68, no. 10, pp. 2224-2241, 2005.

[7] M. P. Jackson, R. J. Neill, A. D. O’Brien, R. K. Holmes, and J. W. Newland, "Nucleotide sequence analysis and comparison of the structural genes for Shiga-like toxin I and Shiga-like toxin II encoded by bacteriophages from Escherichia coli 933," FEMS Microbiology Letters, vol. 44, no. 1, pp. 109-114, 1987.

[8] V. L. Tesh and A. D. O'Brien, "The pathogenic mechanisms of Shiga toxin and the Shiga-like toxins," Molecular Microbiology, vol. 5, no. 8, pp. 1817-1822, 1991.

[9] D. Karpman, H. Council, M. Svensson, F. Scheutz, P. Aim, and C. Svanborg, "The role of lipopolysaccharide and Shiga-like toxin in a mouse model of Escherichia coli O157:H7 infection," Journal of Infectious Diseases, vol. 175, no. 3, pp. 611-620, 1997.

[10] T. K. Mcdaniel, K. G. Jarvis, M. S. Donnenberg, and J. B. Kaper, "A genetic locus of enterocyte effacement conserved among diverse enterobacterial pathogens," Proceedings of the National Academy of Sciences of the United States of America, vol. 92, no. 5, pp. 1664-1668, 1995.

[11] S. J. Elliott, L. A. Wainwright, T. K. McDaniel et al., “The complete sequence of the locus of enterocyte effacement (LEE) from enteropathogenic Escherichia coli E2348/69," Molecular Microbiology, vol. 28, no. 1, pp. 1-4, 1998.

[12] J. B. Kaper, J. P. Nataro, and H. L. T. Mobley, "Pathogenic Escherichia coli," Nature Reviews Microbiology, vol. 2, no. 2, pp. 123-140, 2004.

[13] J.-P. Nougayrède, P. J. Fernandes, and M. S. Donnenberg, "Adhesion of enteropathogenic Escherichia coli to host cells," Cellular Microbiology, vol. 5, no. 6, pp. 359-372, 2003.
[14] S. J. Daniell, E. Kocsis, E. Morris, S. Knutton, F. P. Booy, and G. Frankel, "3D structure of EspA filaments from enteropathogenic Escherichia coli," Molecular Microbiology, vol. 49, no. 2, pp. 301-308, 2003.

[15] W. A. Ferens and C. J. Hovde, "Escherichia coli O157:H7: animal reservoir and sources of human infection," Foodborne Pathogens and Disease, vol. 8, no. 4, pp. 465-487, 2011.

[16] G. Bretschneider, E. M. Berberov, and R. A. Moxley, "Isotypespecific antibody responses against Escherichia coli O157:H7 locus of enterocyte effacement proteins in adult beef cattle following experimental infection," Veterinary Immunology and Immunopathology, vol. 118, no. 3-4, pp. 229-238, 2007.

[17] S. W. Naylor, A. Flockhart, P. Nart et al., "Shedding of Escherichia coli O157:H7 in calves is reduced by prior colonization with the homologous strain," Applied and Environmental Microbiology, vol. 73, no. 11, pp. 3765-3767, 2007.

[18] W. C. Cray Jr. and H. W. Moon, "Experimental infection of calves and adult cattle with Escherichia coli O157:H7," Applied and Environmental Microbiology, vol. 61, no. 4, pp. 1586-1590, 1995.

[19] M. W. Sanderson, T. E. Besser, J. M. Gay, C. C. Gay, and D. D. Hancock, "Fecal Escherichia coli O157:H7 shedding patterns of orally inoculated calves," Veterinary Microbiology, vol. 69, no. 3, pp. 199-205, 1999.

[20] P. M. van Diemen, F. Dziva, A. Abu-Median et al., "Subunit vaccines based on intimin and Efa-1 polypeptides induce humoral immunity in cattle but do not protect against intestinal colonisation by enterohaemorrhagic Escherichia coli O157:H7 or O26:H," Veterinary Immunology and Immunopathology, vol. 116, no. 12, pp. 47-58, 2007.

[21] T. N. McNeilly, M. C. Mitchell, T. Rosser et al., "Immunization of cattle with a combination of purified intimin-531, EspA and Tir significantly reduces shedding of Escherichia coli O157:H7 following oral challenge," Vaccine, vol. 28, no. 5, pp. 1422-1428, 2010.

[22] D. A. Vilte, M. Larzábal, S. Garbaccio et al., "Reduced faecal shedding of Escherichia coli O157:H7 in cattle following systemic vaccination with $\gamma$-intimin $\mathrm{C}_{280}$ and EspB proteins," Vaccine, vol. 29, no. 23, pp. 3962-3968, 2011.

[23] D. A. Vilte, M. Larzábal, U. B. Mayr et al., "A systemic vaccine based on Escherichia coli O157:H7 bacterial ghosts (BGs) reduces the excretion of E. coli O157:H7 in calves," Veterinary Immunology and Immunopathology, vol. 146, no. 2, pp. 169-176, 2012.

[24] T. S. Agin, C. Zhu, L. A. Johnson, T. E. Thate, Z. Yang, and E. C. Boedeker, "Protection against hemorrhagic colitis in an animal model by oral immunization with isogeneic rabbit enteropathogenic Escherichia coli attenuated by truncating intimin," Infection and Immunity, vol. 73, no. 10, pp. 6608-6619, 2005.

[25] M. A. Davis, D. H. Rice, H. Sheng et al., "Comparison of cultures from rectoanal-junction mucosal swabs and feces for detection of Escherichia coli $\mathrm{O} 157$ in dairy heifers," Applied and Environmental Microbiology, vol. 72, no. 5, pp. 3766-3770, 2006.

[26] Ø. Olsvik, E. Rimstad, E. Hornes et al., "A nested PCR followed by magnetic separation of amplified fragments for detection of Escherichia coli Shiga-like toxin genes," Molecular and Cellular Probes, vol. 5, no. 6, pp. 429-435, 1991.

[27] A. W. Paton and J. C. Paton, "Detection and characterization of shiga toxigenic Escherichia coli by using multiplex PCR assays for stx1, stx2, eaeA, enterohemorrhagic E. coli hlyA, rfbO111, and rfbO157," Journal of Clinical Microbiology, vol. 36, no. 2, pp. 598602, 1998. 
[28] M. Blanco, J. E. Blanco, A. Mora et al., "Serotypes, virulence genes, and intimin types of Shiga toxin (verotoxin)-producing Escherichia coli isolates from cattle in Spain and identification of a new intimin variant gene (eae- $\xi)$," Journal of Clinical Microbiology, vol. 42, no. 2, pp. 645-651, 2004.

[29] D. A. Vilte, M. Larzábal, Á. A. Cataldi, and E. C. Mercado, "Bovine colostrum contains immunoglobulin G antibodies against intimin, EspA, and EspB and inhibits hemolytic activity mediated by the type three secretion system of attaching and effacing Escherichia coli," Clinical and Vaccine Immunology, vol. 15, no. 8, pp. 1208-1213, 2008.

[30] P. Nart, N. Holden, S. P. McAteer et al., "Mucosal antibody responses of colonized cattle to Escherichia coli O157-secreted proteins, flagellin, outer membrane proteins and lipopolysaccharide," FEMS Immunology and Medical Microbiology, vol. 52, no. 1, pp. 59-68, 2008.

[31] G. E. P. Box and D. R. Cox, "An analysis of transformations," Journal of the Royal Statistical Society, Series B: Methodological, vol. 26, pp. 211-252, 1964.

[32] R. C. Littell, P. R. Henry, and C. B. Ammerman, "Statistical analysis of repeated measures data using SAS procedures," Journal of Animal Science, vol. 76, no. 4, pp. 1216-1231, 1998.

[33] S. R. Searle, Linear Models, John Wiley \& Sons, 1971.

[34] M. G. Kenward and J. H. Roger, "Small sample inference for fixed effects from restricted maximum likelihood," Biometrics, vol. 53, no. 3, pp. 983-997, 1997.

[35] I. Loureiro, G. Frankel, J. Adu-Bobie, G. Dougan, L. R. Trabulsi, and M. M. S. Carneiro-Sampaio, "Human colostrum contains IgA antibodies reactive to enteropathogenic Escherichia coli virulence-associated proteins: Intimin, BfpA, EspA, and EspB," Journal of Pediatric Gastroenterology and Nutrition, vol. 27, no. 2, pp. 166-171, 1998.

[36] M. B. Martinez, C. R. Taddei, A. Ruiz-Tagle, L. R. Trabulsi, and J. A. Girón, "Antibody response of children with enteropathogenic Escherichia coli infection to the bundle-forming pilus and locus of enterocyte effacement-encoded virulence determinants," Journal of Infectious Diseases, vol. 179, no. 1, pp. 269-274, 1999.

[37] Y. Li, E. Frey, A. M. R. Mackenzie, and B. B. Finlay, "Human response to Escherichia coli $\mathrm{O} 157: \mathrm{H} 7$ infection: antibodies to secreted virulence factors," Infection and Immunity, vol. 68, no. 9, pp. 5090-5095, 2000.

[38] E. A. Dean-Nystrom, L. J. Gansheroff, M. Mills, H. W. Moon, and A. D. O'Brien, "Vaccination of pregnant dams with intimin ${ }_{\mathrm{O} 157}$ protects suckling piglets from Escherichia coli O157:H7 infection," Infection and Immunity, vol. 70, no. 5, pp. 2414-2418, 2002.

[39] N. A. Judge, H. S. Mason, and A. D. O’Brien, "Plant cellbased intimin vaccine given orally to mice primed with intimin reduces time of Escherichia coli O157:H7 shedding in feces," Infection and Immunity, vol. 72, no. 1, pp. 168-175, 2004.

[40] A. Cataldi, T. Yevsa, D. A. Vilte et al., "Efficient immune responses against Intimin and EspB of enterohaemorragic Escherichia coli after intranasal vaccination using the TLR2/6 agonist MALP-2 as adjuvant," Vaccine, vol. 26, no. 44, pp. 5662-5667, 2008.

[41] S. R. Cook, P. K. Maiti, R. DeVinney, E. Allen-Vercoe, S. J. Bach, and T. A. McAllister, "Avian- and mammalian-derived antibodies against adherence-associated proteins inhibit host cell colonization by Escherichia coli O157:H7," Journal of Applied Microbiology, vol. 103, no. 4, pp. 1206-1219, 2007.
[42] K. P. Kenny, T. Tollersrud, and F. D. Bastida-Corcuera, "The enhancement of bovine mammary gland immunity through vaccination," in Bovine Medicine: Diseases and Husbandry of Cattle, A. H. Andrews, R. W. Blowey, and R. G. Eddy, Eds., Blackwell Science, Oxford, UK, 2008.

[43] J. Cervenak and I. Kacskovics, "The neonatal Fc receptor plays a crucial role in the metabolism of IgG in livestock animals," Veterinary Immunology and Immunopathology, vol. 128, no. 1-3, pp. 171-177, 2009.

[44] J. E. Butler, "Bovine immunoglobulins: an augmented review," Veterinary Immunology and Immunopathology, vol. 4, no. 1-2, pp. 43-152, 1983.

[45] M. A. Hoffman, C. Menge, T. A. Casey, W. Laegreid, B. T. Bosworth, and E. A. Dean-Nystrom, "Bovine immune response to Shiga-toxigenic Escherichia coli O157:H7," Clinical and Vaccine Immunology, vol. 13, no. 12, pp. 1322-1327, 2006. 

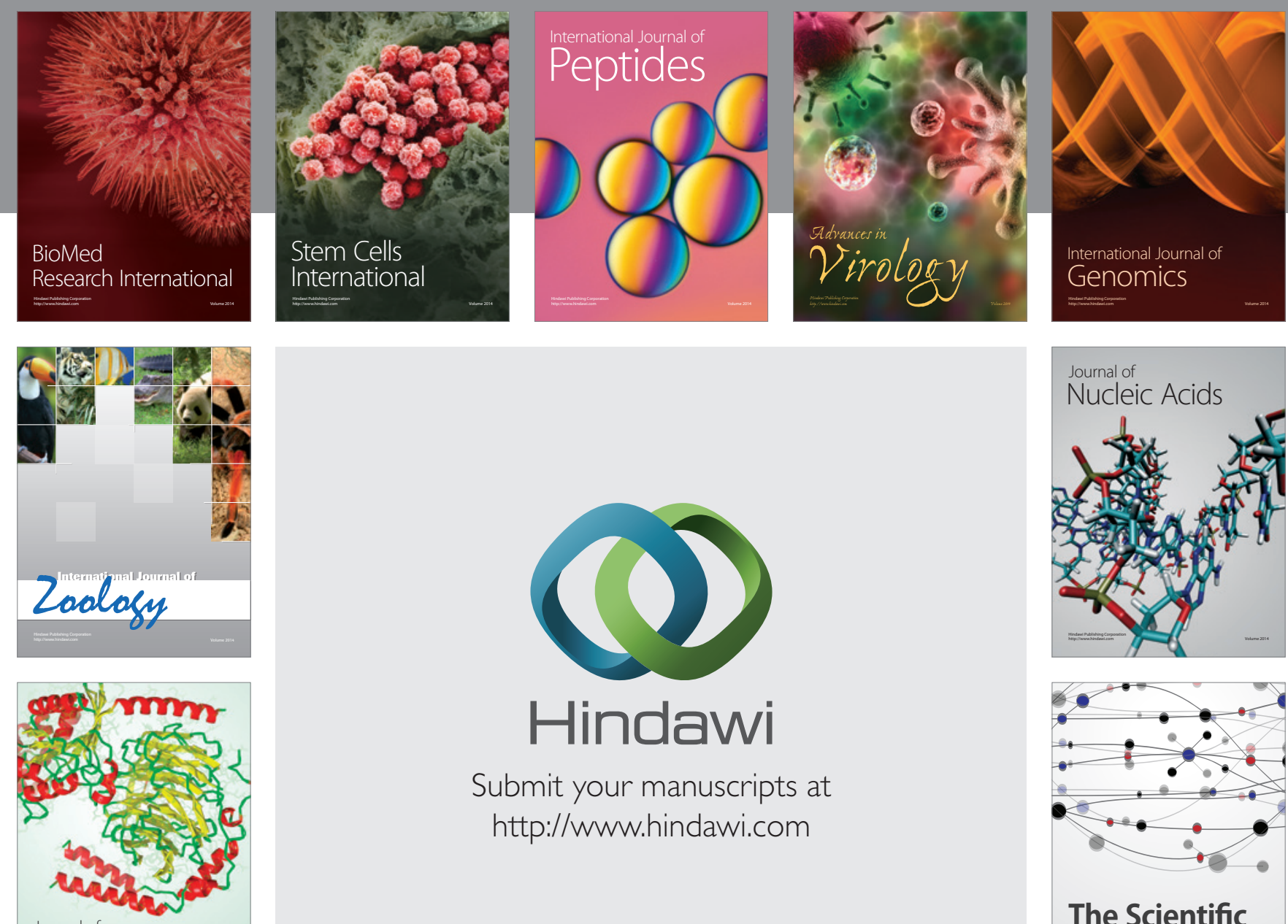

Submit your manuscripts at

http://www.hindawi.com

Journal of
Signal Transduction
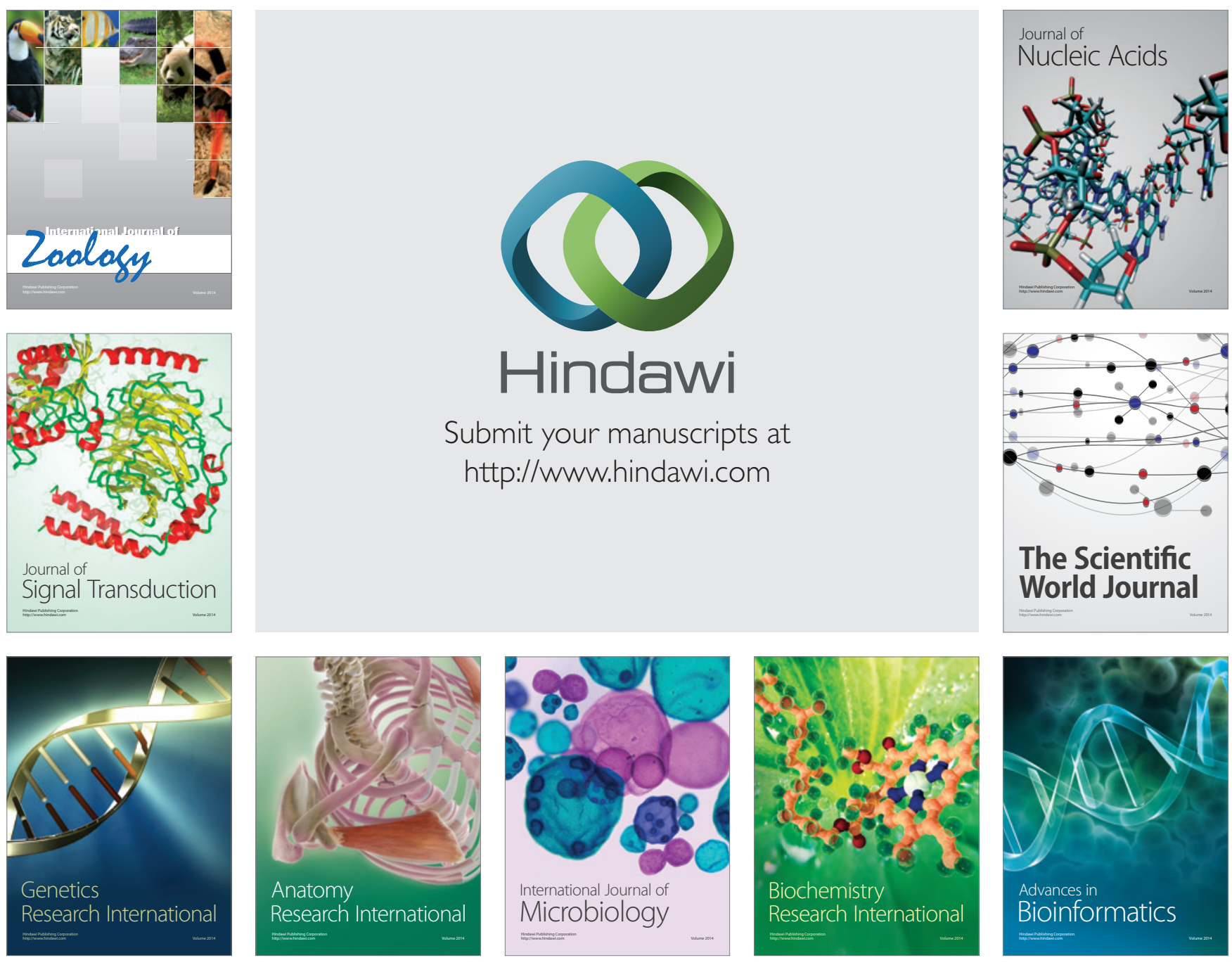

The Scientific World Journal
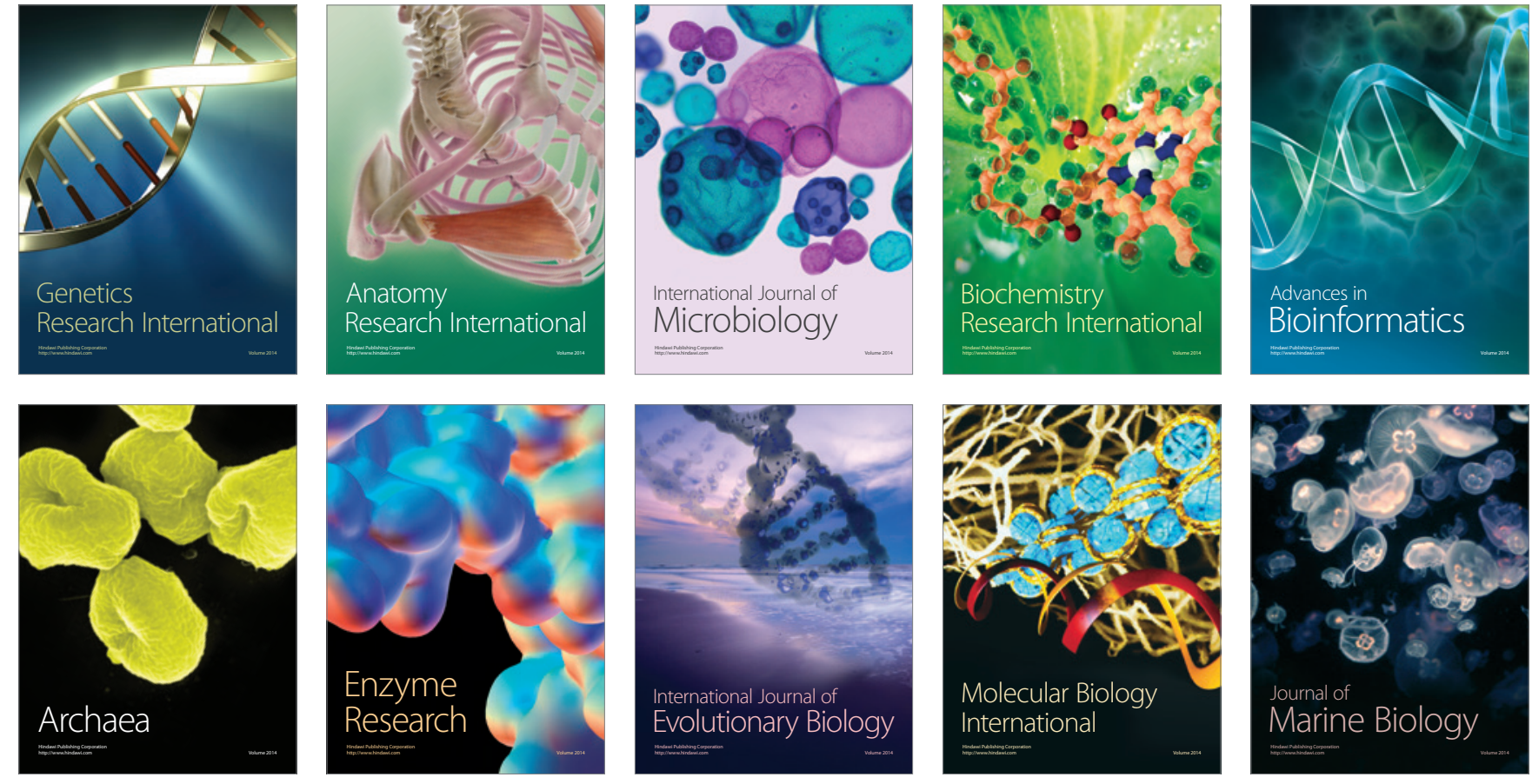